\title{
Foundations of the DEFT Project: tertiary educators Developing Expertise Fostering Thinking
}

\author{
Judy-anne Osborn ${ }^{\mathrm{a}}$, Jo-Ann Larkins ${ }^{\mathrm{b}}$, Bonnie McBain ${ }^{\mathrm{e}}$, Peter Ellerton ${ }^{\mathrm{d}}$, Joel Black ${ }^{\mathrm{b}}$, Naomi \\ Borwein $^{\mathrm{c}}$, Florian Breuer ${ }^{\mathrm{a}}$, and Malcolm Roberts ${ }^{\mathrm{a}}$ \\ Corresponding author: Judy-anne.Osborn@newcastle.edu.au \\ a School of Mathematical and Physical Sciences, University of Newcastle, Callaghan NSW 2308, Australia. \\ ${ }^{\mathrm{b} S}$ School of Engineering, Information Technology and Physical Sciences, Federation University, Churchill, VIC, \\ 3842, Australia. \\ 'Faculty of Education, Western University, London, Ontario N6G1G7, Canada. \\ dUniversity of Queensland Critical Thinking Project, University of Queensland, Saint Lucia QLD 4072, \\ Australia.

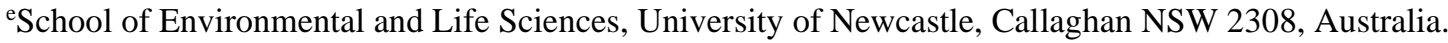

Keywords: teaching for thinking, critical thinking, community of practice $(\mathrm{CoP})$, praxis, expertise, scholarship of teaching and learning (SoTL), participatory action research.

\section{“...practice does not make perfect in the absence of understanding." Deanna Kuhn, 1999}

\begin{abstract}
We describe the rationale, creation, and activity of a long-term co-constructed voluntary professional development initiative for tertiary educators. This is a Community of Practice (CoP) formed to investigate "thinking" as a topic which may be explicitly taught. The aim of this paper is to share the value of this CoP in one context and insights into how similar approaches may be useful to other tertiary educators. The project has run for a year to date, involving a small but growing collective of tertiary educators, with members from one Canadian and several Australian Universities. Our methodology is participatory: we regularly meet, reflect, and record our reflections. Our records contain data relating to our motivation, our insights, and the impact of these upon our choices in our teaching practices. In particular, our rationale includes the mutual desire to invest in developing understanding of our teaching challenges, to enable us to create thoughtful teaching approaches fit for our purposes and contexts. Hence, the central focus of our CoP is the Development of our Expertise in Fostering Thinking (DEFT). This focus has illuminated gaps in existing scholarly literature pertaining to communal development of theory, personal development of schemata, capacity for reflexivity, and instantiation in our disciplines. Opportunities and risks associated with our other sources of professional learning are identified and discussed. We elaborate on a doublelayered approach, in which we explore the construction of our own schemata as a precursor to helping students build their schemata as a foundation for their own understanding, and the role of flexible, critical, and creative thinking on our part. We utilise the scholarship of expertise, frequently returning to such questions as "How do we know what our students are thinking?" Insights gleaned from our reflections are shared, and recommendations are presented on the formation of similar projects.
\end{abstract}

\section{Introduction}

\section{Overview}

The story that we tell here is an evolving community of practice, of eight academics collectively inventing and implementing a methodology for professional development as educators in Universities around the world. For us, professional development constitutes the processes, both formal and informal, by which professionals improve their practice throughout their careers. This is a generalisation of the definition given in Czerniawski, Guberman and 
MacPhail (2016). Our approach is a form of participatory action research (Chevalier \& Buckles, 2019). This is a transformative methodology that marries research to vocation, which is useful to us in ways that other forms of professional development available to us are often not. In particular, our project focuses upon a long-term goal of developing expertise, rather than on short term interventions to learn specific skills or techniques.

The purpose of this paper is to share the value of our "community of practice", and insight into how it works that may be useful to others. A "community of practice" (CoP) is a notion developed by Lave and Wenger; and described in Wenger's (1999) book on the subject. Communities of practice consist of collections of people who share a joint enterprise and shared repertoire, including shared language, concepts and methods. Distinct communities of practice can overlap. For instance, all the employees of a large company might constitute a $\mathrm{CoP}$, as might all certified practicing accountants. In these overlapping spaces new CoPs can emerge. Communities of practice commonly form organically, and they can also be deliberately fostered. CoPs usually involve members with varying levels and types of expertise. Knowledge in a CoP is collective and is typically both "lived" and "reified" in documentation.

As we develop our practice within our CoP, we are simultaneously working at understanding and theorising this practice: a key concept in this context is that of "schema". We understand "schema" in the sense of Ellerton (2019, p. 6) as "a type of changeable structure representing generic concepts that are held in memory".

Within the concept of schema there are various subtypes, but all pertain to the way knowledge is organised within people's minds. In particular, experts develop schema. As we develop our expertise, we develop our individual schemata, which in turn impacts our pedagogical understandings and teaching practices.

DEFT stands for "Developing Expertise Fostering Thinking'; our aim is to become experts at fostering thinking in our communities, including the communities of students we teach. There is a close connection between expertise and schemata. The schema that experts carry in their minds are organised forms of knowledge that allow the experts to respond flexibly and effectively in their expert contexts. Our context is teaching, specifically teaching for thinking. We want to help students to develop according to their needs in relation to the disciplines we teach, which includes developing their own expertise as appropriate.

The DEFT project and its methodology - as implemented to date - centres upon conversations, held every few weeks, conducted using videoconferencing, supporting the reflections of its members upon their teaching goals and challenges. As with all communities of practice, we are developing a shared language through our practice. Part of that language is the language of schema.

We understand that we are each developing schema, and that our students also need to develop schema. This recognition gives us a point of empathy. As we reorganise and develop our own schema, we experience some of what students are going through as they reorganise and develop their schema.

Although we span four institutions, two countries, several disciplines including Mathematics, Science and English, and our roles within our institutions are varied, there are commonalities to the challenges we face and the drivers that bring us to our work. We all feel time poor, and that academia is an environment in which this is a very common state. We also all feel a 
common imperative to teach well, and to improve our teaching; and we are all curious about teaching and teaching well, and its relationship to learning.

The ethics of this project sits within our participatory action research methodology (Chevalier \& Buckles, 2019), and also the notion of auto-ethnography (Hammersley \& Atkinson, 2007). We are doing auto-ethnography because we are our own subjects. The "participatory" aspect refers to the participants in the research being empowered as people who have input into the research design and are not merely the objects of study (Bryman \& Bell, 2015). "Participatory action research" refers to participatory research in which part of the aim is change for the better for the research participants. Important to our ethics is the fact that we are all authors on this paper, each responsible for its content and able to veto any content that we feel may misrepresent any of us.

This paper is organised as follows. The introduction contains the overview just given followed by an explication of the need for this kind of project in terms of the challenging landscape of academia, and then a description of the broad approach in terms of participatory inquiry. Next the methodology describes first our detailed methods as methodology, and then more depth on conceptual schema and how that fits into the work. Following this is a results and discussion section in which we elucidate more aspects of DEFT as a community of practice. Finally, in the conclusion, we indicate the conditions we see as needed for development of similar communities of practice.

\section{The need: professional development and the challenging landscape of academia}

This section is primarily about the need for this kind of project for academics, but that is necessarily grounded in the needs of our students. Teaching makes a difference to students, and teaching well is a complex and skilled undertaking at any level - tertiary teaching is no exception: see for example Ramsden (2003). A large literature points to the importance of thinking, in particular 'critical thinking' - see Davies and Barnett (2015). There is also a rich literature on the challenges in disciplinary contexts - see for instance Chambers and Gregory (2006), Murtonen and Salmento (2019) and Selden (2003).

The DEFT project instigation and the ongoing engagement of its members has arisen out of our felt need to create a rich ongoing professional development environment for ourselves as tertiary educators. According to the literature, such an imperative is not unusual amongst tertiary educators - see for instance the large study of pre-service teacher educators in the UK and European context by Czerniawski, Guberman and MacPhail (2016).

The professional development landscape for teaching and learning in Australia has shifted towards largely institution-wide training for new academics, and 'just-in-time, just-for-you' interventions targeted at key areas prioritised by individual universities (Thomas et al., 2016). Approaches which take a 'one-size fits all' short-term model to professional development of learning and teaching are increasingly seen as problematic and out of touch with contemporary imperatives of educational quality (Thomas et al., 2016). According to Bond and Lockee (2018), the traditional short-term workshop format does not lead to successful translation from professional learning to effective teaching practice. "Teaching in higher education is an activity that cannot be reduced to a set of principles of good practice, or prescriptive recipes" (Fanghanel, 2013, p. 62).

In principle, short term interventions are not the only possibility. The options available to higher education academics for their continual professional development include self-directed 
learning, formal professional development courses, and organisational development training (Caffarella \& Zinn, 1999). Conceptually, successful professional development is either constrained or enabled by "(1) people and interpersonal relationships, (2) institutional structures, (3) personal considerations and commitments, and (4) intellectual and psychosocial characteristics" (Caffarella \& Zinn, 1999, p. 243).

Some of the challenges that academics seeking deep professional development grapple with are elements of the challenging modern landscape of academia, see Barcan (2016). Elements of this landscape include "massification", described by Calderon (2018) as the increase in the proportion of the population attending university in many countries, hence an increase in absolute numbers of students without a proportional increase in staff; and "the intensification of academic life", which is described by Hartman and Darab (2012) as a more strongly competing set of roles and responsibilities, including teaching greater numbers of students, new forms of professionalisation with many new associated bureaucratic accountability mechanisms, and pressure towards entrepreneurialism.

The desire to transcend these challenges is reflected in the literature, evidenced by terms such as "slow scholarship", "slow pedagogy" and "Scholarship of Teaching and Learning (SoTL). "Slow scholarship" is a movement that calls for slowing down and concentrating more deeply on the most valued aspects of scholarship, analogous with the "slow food" movement (Mountz et al., 2015). The related idea of "slow pedagogy" or "slow teaching" is explored in Goldschmidt, Bachman, DiMattio and Warker (2016), in a project that has much in common with the DEFT project. In their paper, Goldschmidt et al. (2016) also talk about the "Scholarship of Teaching and Learning" (SoTL) as more than an area of research, but also as a means to make teaching more visible and more valued.

In advocating for a place for slow scholarship amidst the increasing pace of academic work, Hartman and Darab attest that "the kind of higher order thinking that is a critical part of the scholarly endeavour requires nurture through the provision of sufficient time, unpressured" (2012, p.49). Much has been written on transferring "reflective practice" from theory to practice, Kolb's learning cycle (1984) and Gibb's reflective cycle (1988) being two examples. Each of these uses 'reflection' as a key process, such as through a reflective journal, or structured conversations with colleagues. DEFT is a shared space for reflective practice.

DEFT is both a "community of practice" (Wenger, 1999) and "community of praxis" (Stephen \& Tracey, 2008); where 'praxis' refers to the interleaving of research and practice in a complementary way. It is a space in which we undertake scholarship of learning and teaching. Boose and Hutching (2016) write about SoTL as a "subversive activity" that "invites critical questions about education's purposes, practices and underlying assumptions ... in the name of a shared academic vision" (p. 1). In this sense, DEFT is a reactionary and subversive coconstructed space, aimed at enhancing our professional development, pushing back against the intensification of academic life.

\section{The general approach: DEFT as a participatory inquiry model}

Within the DEFT group, we all want to improve our students' learning through reflection and practice upon our own teaching. But we are diverse in the extent to which we see this process as "research". Our personal experiences of research and research contexts are varied, and we are also diverse in our ontologies (framings of reality) and epistemologies (relationships between the researcher and their ontology). 
In general, a compromise between apparently conflicting paradigms requires a pluralism of approaches (Corry, Porter \& McKenna, 2019). Specifically, Klein and Myers (1999, p. 69) write: "[Q]ualitative research can be done with a positivist, interpretive, or critical stance", with their varying ontologies, epistemologies and methodologies. We straddle the boundary between subjectivity and objectivity, with subjectivity particularly applicable to human experience. 'Interpretive paradigms' focus upon 'meaning' as experienced by human beings (Bevir \& Rhodes, 2002), entailing subjectivity. By comparison, 'realism' focuses upon causal forces (Corry et al., 2019) and speaks more to an aspiration of objectivity.

Recognising the complexities in the above considerations, the DEFT group embarked on a form of participative inquiry, a methodology based on cooperative relations between coresearchers (Heron \& Reason, 1997), envisioned as an inherently self-reflective epistemology, integrating experiential and practical ways of knowing. By constructively interpreting in collaboration with others we seek insight and revelation into the phenomena we investigate (Collis \& Hussey, 2014). Participative inquiry centers the researchers in the methodology, as designers, drivers and data collectors, engaging in a shared experience of collaborative research from question to answer (Bryman \& Bell, 2015). Thus, we explore our commonalities and our differences.

In DEFT, we are a Community of Practice (Wenger, 1999) engaged in scholarship of teaching and learning (SoTL) (Fanghanel, 2013). Because of the interplay between inquiry and teaching, we are a Community of Praxis (Stephen \& Tracey, 2008). 'Praxis' incorporates a values/moral dimension (Grootenboer, 2013), an intention to change the world with our actions (Stephen \& Tracey, 2008), and complexity as outlined originally by Rittel and Webber (1973).

Teaching is a complex context, hence having knowledge of literature about best practice approaches can never be sufficient. Each teaching dilemma is nuanced and context-sensitive, with the success of the approach depending on the perspectives of individual teachers and learners involved. Application of a teaching response is a once-only opportunity. The information required to make teaching decisions is always incomplete. Hence, there are multiple possible definitions of the teaching challenge, with multiple possible and appropriate responses, and the response needed can change depending on context and timing (Wager \& Foote, 2012).

We bring various lenses to the understanding of this complexity. The environmental sustainability literature and discussion therein on "social learning" is one of our sources of inspiration, including Keen, Brown, \& Dyball (2005) and their discussion of five strands of social learning: reflection, systems thinking, integration, negotiation and participation. From this context we bring an awareness of complex issues as context sensitive, with stakeholders holding varying interests and perspectives, making a single definition of the 'problem' impossible. In such contexts, situations are dynamic and every-changing. There may be many possible solutions, but incomplete information means that there is no definitive 'correct' option. There is only one opportunity to apply a solution because the context changes in response, thereby changing any future responses required. We see many parallels with teaching.

The first few members of the DEFT group were from the mathematics community, and the group grew out from there, thus mathematics education literature is also a touchstone for us. Grootenboer (2018), writing within mathematics but with ideas that are more broadly applicable, indicates that in the context of tertiary education there exists no single best practice. 
Learning is more than acquiring facts and skills. Being literate implies a capacity to understand the relevance of facts and skills in context and adapt that knowledge as context changes. Social professional practice (as we do in DEFT) is critical for developing and addressing these challenges (Roth \& Lee, 2002). It means that learning can be adaptive, life-long and foundational i.e. triple loop learning, which seeks to question and change values and social norms, rather than single or double loop learning which addresses only changes in skills, practices, actions or assumptions (Keen et al., 2005).

The DEFT forum enables practitioners involved to (1) examine their teaching approaches by clarifying the context specific teaching dilemma, and (2) collaboratively explore options for responding using the shared experience of those in the discussion through a process of social learning. Social learning, as in DEFT, is a normative activity. DEFT participants engage in critical reflection, which presents an opportunity for transformation to occur (Mezirow, 1991). When our understanding of teaching practice is transformed, we can provide an educational experience that allows students, in turn, to undergo the transformative learning we seek for them.

The ethos of SoTL underlies social learning and transformative learning through reflective examination of one's teaching, to scrutinize questions, refine practices, and critically review and debate in community (Rowland \& Myatt, 2013). It requires practitioners to iteratively reassess the nexus between educational theory, our pedagogies, and lived experience (Holdsworth \& Hegarty, 2016). Fanghanel (2013) espouses SoTL as an "agentic form of inquiry" enabling "a space for dialogic critique of ... investigations into practice that contribute to advancing individual and collective knowledge of the field of higher education" (p. 59). The scholarly methodology of SoTL is a tool for professional development whilst still appreciating the complexities of learning. SoTL acts as a device for transfer of knowledge to new contexts and "provides spaces for interdisciplinary and cross-institutional reflection" (Fanghanel, 2013), p. 62). This is a particularly fruitful space for innovation.

DEFT is a team in accordance with Katzenbach and Smith's definition of "a small number of people with complementary skills who are committed to a common purpose, performance goals, and approach for which they hold themselves mutually accountable" (1993, in Fast, Schildkamp \& van der Veen, 2017, p 737). A systematic review of team-based interventions for professional development in higher education (Gast, Schildkamp \& van der Veen, 2017) highlighted that increases in collegiality and critical reflection, changes in teaching approaches, participant's deeper understanding of their identity as tertiary educators, and the acquisition of new pedagogical knowledge can be achieved using this approach. Harwood and Clarke (2006) argue that "a team approach that is grounded in practice leads to open communication and opportunities for formal and informal professional development" (p. 29). Bond and Lockee (2018) link the concept of communities of practice in the form of Faculty Inquiry Groups to the idea of safe spaces for effective collaborative professional development, sharing and developing practical expertise.

\section{Methodology}

\section{Detailed Methods as Methodology}

In the context of the CoP model for DEFT, 'methods as methodology' suggests the inherent relationship between theory and practice, with a praxis-based methodology being actively developed for professional development, and also to offer a way of mapping and engaging with 
student conceptual knowledge and cognition. Here the inquiry process requires its participants to dismantle and rebuild their own schemata, in order to develop a more versatile collective schema.

Given this heightened interplay between method and methodology, let us first consider the collaboration space that facilitates our process, which is largely remote.

The DEFT group meets online at a regular time every three weeks using an online collaboration tool called 'Vibe' to connect our geographically dispersed group. The group discusses a teaching dilemma of any of the participants. The collective teaching wisdom and experience of the group are brought together to explore the dilemma. An isolated problem then becomes one that others care about. Discussing a current teaching dilemma tends to create insights, timely for implementation into practice.

The group has been active for a year, but it is anticipated that this is a long-term project. As already noted, the inquiry process involves participants dismantling and rebuilding their own schemata on a time frame that is oscillatory and dependent on variables of any given schemata and pedagogical approach. Process-wise, it is possible that schemata are redesigned incrementally and iteratively; conversely, this exploratory process showcases how such schemata can be rendered insufficient and thus suddenly reform. The DEFT process creates time and freedom from interruptions within meetings for deep reflection and collaboration.

Having a range of people with different expertise and experience in the group allows a teaching dilemma to be explored from different perspectives and can raise varying possible responses. It also means that we can identify and challenge each other's assumptions. One person takes on the main organising role (although this can be a shared role when required) to organise meetings, share files and coordinate writing. The group has a lead-mentor (Ellerton) with specific expertise in a) the nature of expertise itself, and b) how expertise is gained (through a $\mathrm{PhD}$ ), as well as c) facilitating and mentoring skills. Through this lexicon of pedagogical knowledge, our mentor is able to help coalesce and translate our recollections of teaching experiences into the 'language' of thinking and learning - as part of our synthesisation process. This allows us to build a shared language, making subsequent analyses easier. Such research mentorship embodies the motile nature of our relationship to student cognition and our approach to a Community of Practice/Praxis.

To further extrapolate on this process, in heightening our self-awareness of our practice and experiences - their meanings, our thoughts and the implications - our mentor partly takes on the role of councillor, by bringing the conversations back to the underlying thinking behind each teaching dilemma we explore. His experience allows him to make connections between experiences or evidence which we would not make with our own expertise. However, there is no expectation that the lead-mentor needs to know everything. Our mentor thus navigates our interdisciplinary discourse on schemata back to the overarching theme of cognition and professional development as an inquiry-based approach to methodology, within the scope of his expertise.

Across the eight members, all provide both leadership and mentoring within the group, at different times and in different ways. Any group member can "hold the floor" during any session, reinforcing perceptions of the group as a safe, egalitarian forum. We designed this approach to develop pedagogical expertise (both individual and collective) to assess and extend responsive teaching methods to enhance 'teaching for thinking'. Pedagogy, by our 
interpretation, is a matter of understanding why we do what we do in terms of student cognitive activity and development. While a curriculum focus is also essential, it is implicit in pedagogical understanding.

An important aspect of the method is the records made of our reflections, and later analysis thereof. These records are a combination of notes taken during meetings, and written reflections afterwards sent back to the group. Written articulation helps clarity. It is these reflections that serve as the data point for the exploration and discussion in this paper, which is guided by important pedagogical problems, like how to best engage with and develop student cognition in the context of tertiary education. At this stage our analysis comprises a reflective process of looking for themes in what we have written. This is not formal coding as might be undertaken in a methodology such as Grounded Theory (Chun Tie, Birks, \& Francis, 2019) but is reminiscent of the initial stages of coding in such approaches.

Central to the development of expertise in any domain is the development of a schematic, integrated understanding of the knowledge, concepts and problem-solution sets of that domain. This understanding is a function of the interplay between theory and practice, in which each informs the construction of the other. Expert practitioners - and those on the path to expertise - bring to their work an understanding that informs their actions, and then engage in reflective phases that allow the results of those actions to modify their understanding. In the expertise literature, this is known as 'deliberate practice'.

The schematic understanding that is the goal of deliberate practice is unique to each domain; but all expert schemata are intricate and detailed, especially in cognitively complex domains such as teaching. Schematic understanding, or cognitive schemata, are not static but dynamic (Barlett, 1932). They are also sensitive to context and contain variables that the context provides, allowing experts to deal with changing circumstances across their domains. Rumelhart and Ortony (1977, p.101) offer four characteristics of cognitive schemata: (1) they contain variables; (2) they may contain other schematic structures within them; (3) the knowledge within them can have levels of abstraction; (4) the knowledge within them is not simply propositional knowledge but (in the case of expert schemata) also experiential knowledge.

The finding that expertise requires schematic knowledge constructed through deliberate practice raises two significant questions. The first question concerns what that understanding looks like in the domain of 'teaching for thinking'. What are the variables within the schema and how are they related to one another? The second question concerns the conditions under which deliberate practice occurs and the nature of that practice in a pedagogical context.

We now consider the practice of using a schema in this study.

\section{Schematic understanding in the domain of teaching for thinking}

Each of us (whether student or professional) must construct our own schematic understanding. It is not possible to make someone an expert, as no one can be made to undergo deliberate practice. For this reason, each schema is unique. But that does not mean there cannot be a common beginning or a normalisation of understanding between experts. One of us (Ellerton) has developed a schematic structure intended to represent a beginning point for deliberative practice. This schema is in use in a variety of current professional development programs for educators throughout Australia and internationally. It represents a candidate schema for 
expertise from which educators can develop their own understanding of their practice. A simplified representation of the schema is presented here as Figure 1.

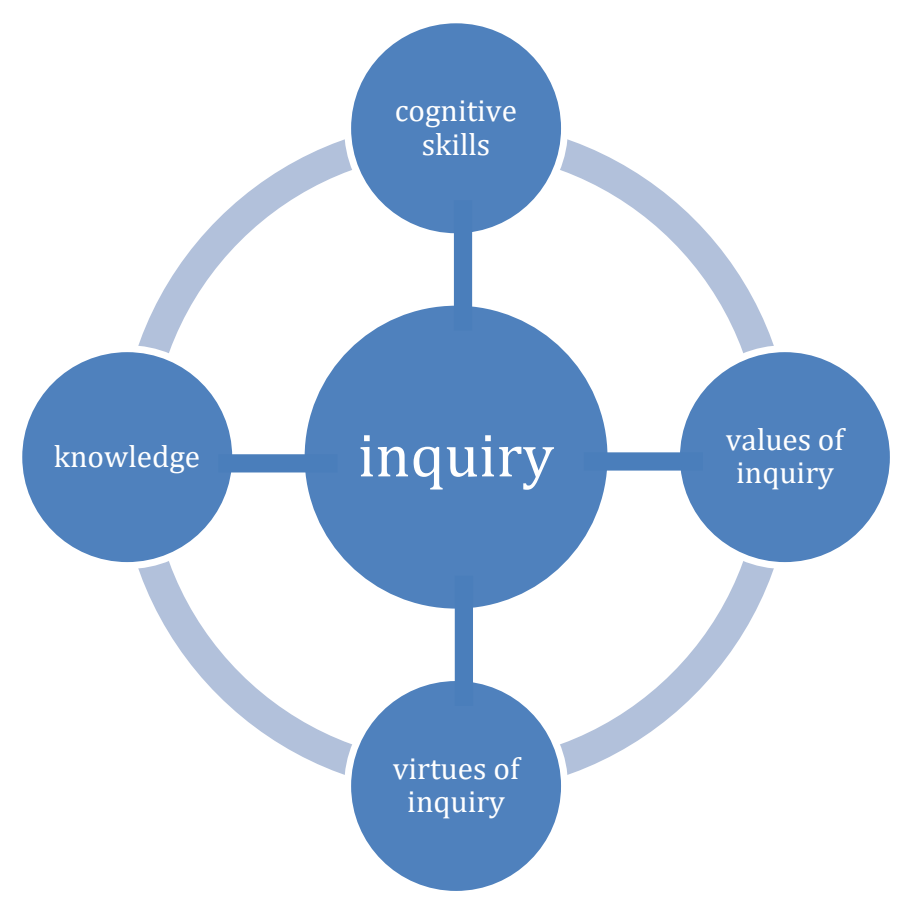

Figure 1. A candidate schema for pedagogical expertise in teaching for thinking (Ellerton, 2019).

Within DEFT we have focussed on three of these elements and the relationships between them: knowledge, cognitive skills and values of inquiry. Cognitive skills are understood as knowledge manipulation and creation, and include terms such as 'analyse', 'explain', 'evaluate', and 'justify'. The values of inquiry are those things which can be used to construct criteria of evaluation and provide feedback on the quality of thinking. They include terms such as 'clarity', 'precision', 'coherence', 'simplicity', and 'relevance'.

The schema helps give our deliberative inquiry intentionality and precision. It is generative and has provided three key questions which guide deliberate practice toward individual member schematic construction:

Q1: How do you know that students are thinking in your classroom?

Q2: How do you plan for that thinking to occur?

Q3: How do you provide students with feedback on the quality of their thinking?

These questions relate to our own practice, and so we are more concerned to look inwards towards our own understanding and the shared understanding of members, than to seek externally for models of teaching.

It is important to note that questions such as 'What are students thinking?' pertain not only to learning skills and knowledge, but also include other critical elements influencing the success of learning, such as beliefs and attitudes about the subject, and belief in themselves as learners and practitioners; as described by Grootenboer (2013) in the context of mathematics education. 
The ideas are more generally applicable. In particular, we know that as teachers our own experiences and identities as learners and practitioners can influence how we respond to students - for a discussion of this general idea exemplified in the mathematics context see Wager \& Foote (2012).

\section{Results and Discussion}

We find that the DEFT methodology has resulted in a sustained community of practice and praxis for more than a year, even in the context of many other competing demands.

Furthermore, DEFT has helped us think in a different way, resulting in conceptual shifts for individual members, and cultural shift collectively. These are the real outcomes of DEFT, and it is these elements which have led to insights (or professional development). Of course, one does not sit down and decide to produce an insight or to transform how one thinks. We noticed, however, that once a safe space had been established, insights began occurring spontaneously as members wrestled with new ideas. We share some of the insights which resulted from our collaborations, in the form of quotes from DEFT members extracted from our records.

One member noted,

One thing that I have gained is from my conversation is ... the meaning of the word schema. It perfectly explains something I've been thinking about. When I'm talking to my students, I'm trying to help them construct their schema. In $3^{\text {rd }}$ year algebra ... build up a schema and not just memorise and play verbal games ... you see it, you have a unit in your head that behaves in certain ways. I had in the past tried to consciously explain this to my students. Hearing this again reminds me of that thinking, and that that's what it's all about.

Another noted that,

I feel like I have this level of confidence from what I had before ... it's not because I've changed, it's that I feel that I have a group around me that I can ask ... it's something that has happened internally to me.

Often DEFT conversations went back and forth. Outwardly they could be perceived as 'messy'. However, this messiness was critical to any outcomes for those participating and is the result of our thinking or perceiving ideas differently. One member noted that,

I'm talking myself into my idea. Sometimes it's necessary to let the idea develop. Sometimes you have to wrestle your way into the idea. Witnessing that wrestling happening becomes part of understanding what the idea is about. To use a mathematical example, the relationship between a theorem and the examples that it came from.

The outcomes of the process often could not be 'measured' in the traditional sense of most professional development. A reliance on traditional evidence of teaching quality can, at worst, divert attention away from a more authentic interrogation of our teaching and its quality. Measures such as 'attendance at workshops' and 'completion of output' were meaningless in the DEFT context. One participant said it this way:

We are constantly dealing with systems where they're always trying to come up with some sort of measure of meeting a goal. That sort of a system really breaks down when it comes to 
"how well did you get inside your students' heads to unravel their misunderstanding and help them rebuild it correctly". There is no way to capture that in any sort of performance management system.

By understanding and renegotiating our own schema about teaching and learning we immerse ourselves in the student experience, understanding how they might feel and what they do whilst they are learning.

The guru doesn't have to have all of the answers [neither does any teacher]. We are not necessarily discussing how schema work so that we can impose this onto classroom management. We are living our own schema - that nexus between our understanding of our curriculum and how we teach the students.

That experience allowed us to articulate with students why it is so uncomfortable to dismantle a schema, but that it's a natural part of the process, a good sign.

To properly learn something, build up a schema, takes a really, really long time ... not just practice that you can do on mental auto-pilot.

We recognise the need for sustained practice that is often gradual, not only seeking that one 'ah ha' moment. We likened the process as slowly dismantling a brick wall and then rebuilding it a different way. That meant the impact of DEFT was, at times, incremental and cumulative, in a way that parallels curricular structure. This understanding helped us have a better understanding of the experience of our students.

We empathise with students who miss a bit and are at risk of dropping out.

Developing a shared and academic vocabulary around our experience was also critical. For one of our members this was the perfect space to:

articulate exactly just what it is I do when I teach. As an instinctive teacher, I know what works but couldn't explain why to others. Finding DEFT at just the right point in my teaching journey gave me a place to explore the why and what of my teaching and find the language for clear explanations of concepts such as schema, discursive teaching, etc...

Another member suggested that this space and its cumulative lexicon has become:

a powerful interdisciplinary tool for theoretical and methodological development.

In this space, members learned to describe their experience so others can appreciate and recognise it, picking up on verbal cues in the way that a conversation is developing, and inserting their experience into the conversation to find relevance in our own practice. This was initially effortful but became rewarding. However, having a shared vocabulary did not always work perfectly. An admission by one member of the group, that 'some of the vocabulary [in the conversation] .... was difficult to understand', is an important demonstration that ongoing effort is required to establish a non-judgemental environment for a free-flowing exchange if it is to be a genuine opportunity to clarify content and generate further discussion.

Having an equal playing field also constituted a safe space - elements contributing to this that were identified by members included respectful communication, the equalising nature of the 
online environment, open attitudes, and willingness to learn. DEFT also filled a need for community for academics who have a teaching focus in a research-oriented setting.

DEFT for me is a distributed online community of practice where I have found "my people" in cyberspace.

The insights gained from DEFT meetings had flow-on effects after the meetings ended. One member noted:

A morning meeting felt like the daily reflections within a religious tradition, in that it planted an idea at the beginning of the day, which could serve as a touchstone during the day to guide reflection-in-the-moment.

In short, the outcomes from the DEFT process contrasted significantly from most of the more traditional professional development opportunities we had experienced with their focus on mechanical tasks such as how to design an intuitive online course site, or how to write a rubric.

In DEFT we try to understand how the thinking part of learning occurs. Discovering that with other people is a different process to just reading and ticking off qualifications attained.

The development of expertise in teaching is a professional goal that takes time, reflection and practice to accomplish. Our experience in the DEFT project is that this process can be effectively supported in a community of practice with the practices outlined in this paper. These practices are reflective: we are our own subjects in this inquiry project. We conclude that we are no less worthy of study than our students.

\section{Conclusion}

The aim of the DEFT project is to help its participants realise our aims to increase our deftness at teaching for thinking, in our tertiary teaching contexts, through a reflective approach within a community of practice and praxis. Our experience is that this aim is met by our methods. As one member articulated:

It's this personally valuable space to me. It's this personal problem-solving arena with colleagues whom I so admire! I like that it keeps happening, but with not too much pressure, but enough of a sense of responsibility to others to keep it happening.

For the DEFT team, and for those who wish to replicate such a group, our results suggest the following are essential to implementing this approach to professional development:

- A dedicated time, at regular intervals and without distraction

- A long-term commitment

- A mentor/provocateur to help test assumptions

- Diversity (e.g. cross discipline, level of experience, international)

- An online space, so that everyone is on an equal playing field

- A safe space, where participants can all feel comfortable and where conversations are respectful

- An open attitude allowing participants to play around with new ideas and possibilities and to authentically share their own perspectives. 


\section{References}

Barcan, R. (2016). Academic life and labour in the new university: Hope and other choices. Routledge.

Barlett, I. L. (1932). Remembering. Cambridge, England: Cambridge University Press.

Bevir, M., \& Rhodes, R. A. (2002). Interpretive theory. in D. Marsh and G. Stoker (eds.), Theories and Methods in Political Science. 2nd ed. London, Macmillan.

Bond, M.A., \& Lockee, B.B. (2018). Evaluating the Effectiveness of Faculty Inquiry Groups as Communities of practice for Faculty Professional Development. Journal of Formative Design in Learning, 2018(2), 1-7. doi: $10.1007 / \mathrm{s} 41686-018-0015-7$

Boose, D., \& Hutchings, P. (2016). The Scholarship of Teaching and Learning as a Subversive Activity. The ISSOTL Journal, 4(1), 1-12. https://doi.org/10.20343/teachlearninqu.4.1.6

Bryman, A., \& Bell, E. (2015). Business Research Methods (4th ed). Oxford, UK: Oxford University Press.

Caffarella, R.S., \& Zinn, L.F. (1999). Professional Development for Faculty: A Conceptual Framework of Barriers and Supports. Innovative Higher Education, 23(4), 241-254.

Calderon, A. (2018). Massification of higher education revisited, Melbourne: RMIT University, 2018.

Chambers, E., \& Gregory, M. (2006). Teaching and learning English literature. Sage.

Chevalier, J. M., \& Buckles, D. J. (2019). Participatory action research: Theory and methods for engaged inquiry. Routledge.

Chun Tie, Y., Birks, M., \& Francis, K. (2019). Grounded theory research: a design framework for novice researchers. SAGE Open Medicine, https://doi.org/10.1177/2050312118822927

Collis, J., \& Hussey, R. (2014). Business Research: A practical guide for undergraduate and postgraduate students (4th ed.) Basingstoke, Hampshire: Palgrave Macmillan.

Corry, M., Porter, S., \& McKenna, H. (2019). The redundancy of positivism as a paradigm for nursing research. Nursing Philosophy, 20(1), e12230.

Czerniawski, G., Guberman, A., \& MacPhail, A. (2016). The professional developmental needs of higher education-based teacher educators: an international comparative needs analysis. European Journal of Teacher Education, 40(1), 127-140. doi:10.1080/02619768.2016.1246528

Davies, M., \& Barnett, R. (Eds.). (2015). The Palgrave handbook of critical thinking in higher education. Springer.

Ellerton, P. (2019). Teaching for thinking: Explaining pedagogical expertise in the development of the skills, values and virtues of inquiry. PhD Thesis, School of Historical and Philosophical Inquiry, The University of Queensland. https://doi.org/10.14264/uql.2019.211

Fanghanel, J. (2013). Going Public with Pedagogical Inquiries: SoTL as a Methodology for Faculty Professional Development. Teaching \& Learning Inquiry: The ISSOTL Journal, 1(1), 59-70.

Gast, I., Schildkamp, K., \& van der Veen, J.T. (2017). Team-based professional Development Interventions in Higher Education: A Systematic Review. Review of educational research, 87(4), 736-767. doi: $10.3102 / 0034654317704306$

Gibbs, G. (1988). Learning by doing: A guide to teaching and learning methods. Further Education Unit, Oxford Polytechnic, UK.

Goldschmidt, M. L., Bachman, J. L., DiMattio, M. J. K., \& Warker, J. A. (2016). Exploring Slow Teaching with an Interdisciplinary Community of Practice. Transformative Dialogues. Teaching \& Learning Journal, 9(1).

Grootenboer, P. (2013). The praxis of mathematics teaching: developing mathematical identities. Pedagogy, Culture \& Society, 21(2), 321-342. doi:10.1080/14681366.2012.759131

Grootenboer, P. (2018). The Praxis of Leading in the Middle. In P. Grootenboer (Ed.), The Practices of School Middle Leadership: Leading Professional Learning (pp. 175-194). Singapore: Springer Singapore.

Hammersley, M. \& Atkinson P. (2007). Ethnography principles in practice. third ed. London: Routledge.

Hartman, Y., \& Darab, S. (2012). A Call for Slow Scholarship: A Case Study on the Intensification of Academic Life and its Implications for Pedagogy. The Review of Education, Pedagogy and Cultural Studies, 34, 49-60. doi: 10.108/10714413.2012.643740

Harwood, T. \& Clarke, J. (2006). Grounding continuous professional development (CPD) in teaching practice. Innovations in Education in Teaching International, 43(1), 29-39. doi: 10.1080/14703290500467400

Heron, J., \& Reason, P. (1997). A Participatory Inquiry Paradigm. Qualitative Inquiry, 3(3), 274-294.

Holdsworth, S., \& Hegarty, K. (2016). From praxis to delivery: a Higher Education Learning Design Framework (HELD). Journal of Cleaner Production, 122, 176-185. doi:https://doi.org/10.1016/j.jclepro.2016.01.074

Keen, M., Brown, V., \& Dyball, R. (2005). Social learning in environmental management: Towards a sustainable future. London: Earthscan.

Klein, H. K., \& Myers, M. D. (1999). A set of principles for conducting and evaluating interpretive field studies in information systems. MIS quarterly, 67-93. 
Kolb, D.A. (1984). Experiential learning: experience as the source of learning and development. Englewood Cliffs, NJ: Prentice Hall.

Kuhn, D. (1999). A Developmental Model of Critical Thinking. Educational Researcher 28(2), 16-46.

Mackey, J., \& Evans, T. (2011). Interconnecting Networks of Practice for Professional Learning. International review of Research in Open and Distance Learning, 12(3), 1-17.

Mezirow, J. (1991). Transformative dimensions of adult learning. San Francisco: Jossey-Bass.

Mountz, A., Bonds, A., Mansfield, B., Loyd, J., Hyndman, J., Walton-Roberts, M., Basu, R., Whitson, R., Hawkins, R., Hamilton, T., \& Curran, W. (2015). For Slow Scholarship: A Feminist Politics of Resistance through Collective Action in the Neoliberal University. ACME: An International Journal for Critical Geographies, 14(4), 1235-1259.

Murtonen, M., \& Salmento, H. (2019). Broadening the Theory of Scientific Thinking for Higher Education. In Redefining Scientific Thinking for Higher Education (pp. 3-29). Palgrave Macmillan.

Ramsden, P. (2003). Learning to teach in higher education. Routledge.

Rittel, H.W.J., \& Webber, M.M. (1973). Dilemmas in a General Theory of Planning. Policy Sciences, 4, 155169.

Roth, W.-M., \& Lee, S. (2002). Scientific literacy as collective praxis. Public Understanding of Science, 11(1), 33-56. doi:10.1088/0963-6625/11/1/302

Rowland, S. L., \& Myatt, P. M. (2014). Getting started in the scholarship of teaching and learning: A "how to" guide for science academics. Biochemistry and Molecular Biology Education, 42(1), 6-14.

Rumelhart, D.E., \& Ortony, A. (1977). The representation of knowledge in memory. In R.C. Anderson, R.J. Spiro \& W.E. Montague (Eds.), Schooling and the acquisition of knowledge (pp. 99-135). Hillsdale, NJ: Erlbaum

Schön, D. A. (1983). The reflective practitioner: How professionals think in action. The University of Michigan: Basic Books.

Selden, A. (Ed.). (2003). Research in Collegiate Mathematics Education (Vol. 5). American Mathematical Soc..

Stephen, K., \& Tracey, J. S. (2008). Personal Praxis. In (pp. 15-35). Leiden, The Netherlands: Brill | Sense.

Thomas, L.K., Harden-Thew, K., Delahunty, J., Dean, B.A (2016). A vision of You-topia: Personalising professional development of teaching in a diverse academic workforce. Journal of University Teaching and Learning Practice, 13(4), 1-12.

Wager, A. A., \& Foote, M. Q. (2012). Locating Praxis for Equity in Mathematics: Lessons From and for Professional Development. Journal of Teacher Education, 64(1), 22-34. doi:10.1177/0022487112442549

Wenger, E. (1999). Communities of practice: Learning, meaning, and identity. Cambridge university press. 